\title{
Pediatric Oxygen Therapy: A Review and Update
}

\author{
Brian K Walsh PhD RRT-NPS RRT-ACCS RPFT AE-C FAARC and Craig D Smallwood RRT
}

\author{
Introduction \\ Assessment of Inadequate Oxygen Delivery \\ Indications \\ Contraindications \\ Goals of Oxygen Therapy \\ Physical Effects of Oxygen \\ Physiologic Effects of Oxygen Therapy \\ Oxygen Toxicity \\ Oxygen Delivery Devices \\ Monitoring of Oxygen Therapy \\ Home Environment \\ Preparation of Oxygen \\ Future \\ Summary
}

\begin{abstract}
Oxygen is a colorless, odorless, tasteless gas that is utilized by the body for respiration. Oxygen has played a major role in respiratory care. Oxygen therapy is useful in treating hypoxemia but is often thought of as a benign therapy. After many years of study, we have learned a great deal of the benefits and potential risk of this powerful drug. Today oxygen gas is cheap, widely available, and easy to administer. Oxygen delivery devices vary in cost from a few cents for a simple nasal cannula to $\$ 25-\$ 50$ for some humidified systems. Undoubtedly, oxygen therapy is an important tool and has saved many lives and improved others. However, oxygen therapy risk, cost, and benefits should be considered in the same way as other drugs and titrated to a measured end point to avoid excessive or inadequate dosing. Withholding oxygen can have a detrimental effect, yet continuing to provide oxygen therapy when it is no longer indicated can prolong hospitalization and increase the cost of care. This comprehensive review begins with an assessment of need and a review of physiologic effects, potential toxicities, and common delivery devices, and it ends with advances in oxygen therapy with a focus on the pediatric patient. Key words: oxygen delivery; oxygen therapy; oxygen; oxygen review; pediatric; gas therapy. [Respir Care 2017;62(6):645-661. (C) 2017 Daedalus Enterprises]
\end{abstract}

\section{Introduction}

In 1774, Joseph Priestley of England discovered the colorless, odorless, tasteless gas that Antoine Lavoisier named oxygen. ${ }^{1}$ Oxygen is a highly reactive non-metallic chemical element of atomic number 8 that readily forms compounds, particularly oxides, with most elements. Oxygen normally exists in the atmosphere as a diatomic gas, $\mathrm{O}_{2}$, and makes up 0.209 the earth's atmosphere by volume and 0.232 by weight. ${ }^{2}$ In 1907, Budin recommended ox- ygen "supplied through a funnel, the large opening of which is placed beside the infant's face" for the treatment of cyanotic episodes in newborns. Nearly 150 years after its discovery, Finnish pediatrician Arvo Ylppö recommended the intragastric administration of this gas to infants. ${ }^{4}$ It was not until 1934 that Dr Julius Hess, Chief of Pediatrics at the Michael Reese Hospital in Chicago, created the first inhaled oxygen delivery device for infants and young children. ${ }^{5}$ His "oxygen box," which consisted of a metal hood with a small window, was the first oxygen 
chamber used within an incubator. ${ }^{5}$ The device was criticized both for making it difficult to view the infant and for its inability to provide high oxygen concentrations, but it paved the way for the development of oxygen administration devices in pediatrics. By the 1940s, a commercially available incubator capable of providing and facilitating oxygen therapy for the treatment of cyanosis, apnea, and periodic breathing in newborns was the standard of care. ${ }^{3,6}$ Further development and use of these delivery devices has resulted in significant health-care benefits, including a reduction in mortality. Today the administration of oxygen by inhalation continues to play an essential role in the survival of infants and children. ${ }^{4,7}$

Before the 1960s and 1970s, oxygen administration was guided by the clinical observation of skin color, as well as the breathing frequency, regularity, and work of breathing. It was not until the 1960s and 1970s that technology (microsampling of blood gases, transcutaneous oxygen monitoring, and later pulse oximetry) became available for more precise monitoring of the physiologic effect. ${ }^{8}$

The overall goal of oxygen therapy is to achieve adequate oxygenation using the lowest fraction of delivered oxygen, often referred to as $\mathrm{F}_{\mathrm{DO}_{2}}$. However, achieving this goal is complicated by several factors. Despite more than 75 years of routine oxygen administration in pediatrics, normoxia (administration that avoids the detrimental effects of hypoxia on the one hand and those caused by hyperoxia on the other) has not yet been clearly defined, ${ }^{9-11}$ leading to wide variations in practice. ${ }^{12}$ Even the term adequate oxygenation is not clear. ${ }^{13}$ Adequate oxygenation in the simplest terms is the balance between oxygen delivery to the tissue and their rate of oxygen consumption. Another definition may include oxygen delivery that allows the cells to consume oxygen for energy normally. If adequate oxygen delivery is not provided, anaerobic metabolism and cell death occur. There are 2 components that make up oxygen delivery: (1) oxygen-carrying capacity and (2) perfusion. This means that someone can have adequate

\footnotetext{
The authors are affiliated with the Division of Critical Care Medicine, Department of Anesthesiology, Perioperative and Pain Medicine, Boston Children's Hospital, Boston, Massachusetts and Harvard Medical School, Boston, Massachusetts.
}

Both authors have disclosed a relationship with Vapotherm.

Dr Walsh presented a version of this paper at the 55th RESPIRATORY CARE Journal Conference, "Pediatric Respiratory Care," held June 10-11, 2016, in St Petersburg, Florida.

Correspondence: Division of Critical Care Medicine, Department of Anesthesiology, Pain and Perioperative Medicine, MSICU Office, Bader 634, Boston Children's Hospital, 300 Longwood Avenue, Boston, MA 02115. E-mail: brian.walsh@ childrens.harvard.edu.

DOI: $10.4187 /$ respcare. 05245 oxygen carrying capacity but low cardiac output and die from inadequate oxygen delivery, and vice versa. Other factors that complicate achievement of oxygen therapy goals include patient size and tolerance of delivery devices; variability in the use of delivery devices, suggesting that clinicians often lack adequate knowledge in the use of oxygen delivery equipment ${ }^{14}$; and the lack of training in the concepts of oxygen delivery and equipment used to monitor the effects of oxygen therapy. ${ }^{15}$ This review will attempt to address the benefits, harms, and principles of oxygen therapy.

\section{Assessment of Inadequate Oxygen Delivery}

To identify a patient's need for oxygen, several physical signs and laboratory values can be assessed. Hypoxemia is often diagnosed by a lower than normal $\mathrm{P}_{\mathrm{aO}}$, most often considered $<80 \mathrm{~mm} \mathrm{Hg}$. A routinely sited indication for providing oxygen is when $\mathrm{P}_{a \mathrm{O}}$ is $<60 \mathrm{~mm} \mathrm{Hg}$ in children, yet $\mathrm{P}_{\mathrm{aO}}$ alone is inadequate to determine oxygen delivery. Oxygen delivery is determined by the concentration of hemoglobin in the blood; its oxygen saturation; the rate of blood circulation; and, last, the efficiency with which oxygen is unloaded from the hemoglobin to the tissues. Oxygen delivery is often expressed in the following equation: $\mathrm{DO}_{2}=\mathrm{CO}\left[\left(\mathrm{Hb} \times \mathrm{S}_{\mathrm{aO}_{2}} \times 1.34\right)+\left(\mathrm{P}_{\mathrm{aO}_{2}} \times 0.0031\right)\right]$, where $\mathrm{DO}_{2}$ is the rate of oxygen delivery, $\mathrm{Hb}$ is the hemoglobin concentration, and $\mathrm{S}_{\mathrm{aO}_{2}}$ is the percentage of saturated hemoglobin with oxygen. ${ }^{16}$ The 1.34 represents the oxygen carrying capacity of the hemoglobin. The $\mathrm{P}_{\mathrm{aO}}$ is the $\mathrm{P}_{\mathrm{O}_{2}}$ in the arterial blood. The 0.003 is the solubility coefficient for oxygen in blood. $\mathrm{CO}$ is cardiac output. Therefore, you can see within this equation that $\mathrm{P}_{\mathrm{aO}_{2}}$ is based on a relatively insignificant amount dissolved within the blood. In a patient who is anemic or hypovolemic, has an abnormal hemoglobin with increased affinity for oxygen, or has a low $\mathrm{CO}$, his/her oxygen delivery may be inadequate even in the presence of a normal $\mathrm{P}_{\mathrm{aO}}$. Inadequate oxygen delivery in this case is often referred to as hypoxia. We will discuss hypoxia in a little more detail in the upcoming paragraphs.

Since a $\mathrm{P}_{\mathrm{aO}_{2}}$ of 60 and 80 corresponds with a noninvasive $\mathrm{S}_{\mathrm{pO}_{2}}$ value of approximately 90 and $95 \%$, respectively, in the patient with a normal $\mathrm{pH}, \mathrm{P}_{\mathrm{CO}_{2}}$, temperature, and diphosphoglycerate, oximetry is often use to help identify hypoxemia. Pulse oximetry has its limitations and is known to be inaccurate in carbon monoxide poisoning, and the oxyhemoglobin dissociation curve can shift left (increased affinity for $\mathrm{O}_{2}$ ) or right (decreased affinity for $\left.\mathrm{O}_{2}\right) .{ }^{17}$ These patient conditions need to be considered during the assessment of adequate oxygen delivery.

Underlying pathophysiologic mechanisms of hypoxemia are: pulmonary disease, hypoventilation, uneven matching of ventilation to perfusion, diffusion defects, intrapulmonary shunts or "right to left" cardiac shunts, or reduced 
Table 1. Potential Causes of Hypoxemia, the Effects of Each of the Types of Hypoxemia on the Alveolar-to-Arterial Gradient, and the Potential Role Oxygen Therapy May Play If Applied to the Patient

\begin{tabular}{lll}
\hline \hline Causes of Hypoxemia & $\begin{array}{c}\text { Effects on A-a } \\
\text { Gradient }\end{array}$ & $\begin{array}{c}\text { Effects on Oxygen } \\
\text { Therapy }\end{array}$ \\
\hline Reduced $\mathrm{F}_{\mathrm{IO}_{2}}$ & $\begin{array}{c}\text { Unchanged or } \\
\text { reduced }\end{array}$ & Resolved \\
Hypoventilation & $\begin{array}{l}\text { Unchanged } \\
\text { Increased }\end{array}$ & $\begin{array}{l}\text { Alleviated } \\
\text { Partially alleviated } \\
\text { (common) }\end{array}$ \\
$\dot{\mathrm{V}}_{\mathrm{A}} / \mathrm{Q}$ mismatch & Increased & Cannot be alleviated \\
$\mathrm{R}-\mathrm{L}$ shunt & Increased & Alleviated (rare) \\
Diffusion limitations & & \\
\hline $\mathrm{A}-\mathrm{a}=$ alveolar-to-arterial & & \\
$\dot{\mathrm{V}}_{\mathrm{A}} / \mathrm{Q}=$ ventilation/perfusion ratio \\
$\mathrm{R}-\mathrm{L}=$ right-to-left & & \\
\hline
\end{tabular}

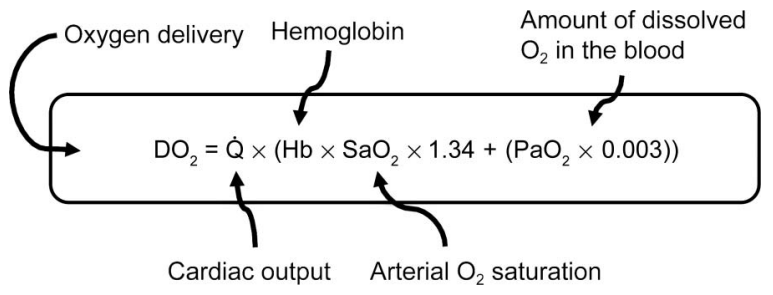

Fig. 1. Equation for oxygen delivery.

oxygen-carrying capacity due to anemia or abnormal blood hemoglobin. ${ }^{18}$ See Table 1 for the mechanisms leading to hypoxemia and, more importantly, the proposed effects that oxygen therapy will have on each type of hypoxemia. ${ }^{19}$ Physical signs, such as cyanosis, confusion, tachycardia, retractions, nasal flaring, and expiratory grunting (infants) can be indications of an oxygen need. ${ }^{20-22}$ Hypoxia is more serious and is defined as a deficit of oxygen at the cellular level; it is commonly caused by hypoxemia or hypoxia due to inadequate oxygen delivery due to high metabolic demand, such as sepsis, or cardiac performance, such as heart failure, or localized decreases in perfusion, such as stroke. ${ }^{23,24}$ It is often a proper assumption that if left untreated, severe hypoxia can lead to serious and permanent brain injury and death. ${ }^{23}$ It must be emphasized that hypoxia is determined not by $\mathrm{P}_{\mathrm{aO}_{2}}$ or $\mathrm{S}_{\mathrm{pO}_{2}} / \mathrm{S}_{\mathrm{aO}_{2}}$ alone but also by hemoglobin, oxygen extraction, and metabolic demand of the body as described previously. Figure 1 describes the components that make up oxygen delivery.

Since this is a review on oxygen therapy, we will be primarily focusing on the arterial oxygen saturation or reversing hypoxemia and secondarily the amount of oxygen dissolved in the blood. Although other factors are important to consider when you have reversed the hypoxemia but hypoxia remains, they are outside of the scope of this review.

\section{Indications}

Oxygen therapy is indicated when there is an abnormally low concentration of oxygen within the arterial blood, otherwise known as hypoxemia. Oxygen is necessary for adequate metabolism of carbohydrates and the production of adenosine triphosphates. When oxygen levels do not meet the requirements of body function, tissue hypoxia occurs. ${ }^{25}$ This hypoxia may cause a series of undesirable problems, such as localized vasodilation, pulmonary vasoconstriction, metabolic acidosis, tissue necrosis, an increased risk of kernicterus, and impairment of surfactant production. Hypoxia may result in brain injury. The purpose of supplying additional oxygen is to eliminate hypoxemia that may lead to tissue hypoxia.

\section{Contraindications}

Although there are very few contraindications to oxygen therapy, in congenital heart disease patients who have ductal-dependent lesions oxygen therapy may cause overcirculation within the pulmonary system as a potent pulmonary vasodilator. In premature neonates, lower $\mathrm{S}_{\mathrm{pO}_{2}}$ may be targeted to reduce the toxic effects of oxygen therapy, such as retinopathy of prematurity or bronchopulmonary dysplasia.

\section{Goals of Oxygen Therapy}

The goal of oxygen administration is to achieve adequate tissue oxygenation. The system used to provide supplemental oxygen must be appropriate to the patient's size and clinical condition. Selection of the oxygen delivery device and flow is targeted to meet the specific physiologic needs and therapeutic goals of each patient. ${ }^{26} \mathrm{Un}$ fortunately, adverse reactions from the therapeutic use of oxygen are not well documented in pediatric patients. Therefore, it is imperative that oxygen therapy be provided at accurate and safe levels with the lowest possible fractional concentration of inspired oxygen $\left(\mathrm{F}_{\mathrm{IO}_{2}}\right)$.

\section{Physical Effects of Oxygen}

Oxygen is a dry gas. Adequate humidification is required by the airway to maintain proper ciliary function, prevent squamous epithelial changes, prevent dehydration and thickening of secretions, minimize atelectasis and tracheitis, and prevent heat loss. ${ }^{27-30}$ Moreover, inadequate humidification may contribute to staphylococcal sepsis due to drying and cracking of the mucosa. ${ }^{31}$ The nasal mucosa is designed to warm and humidify breathing gas before entering the conducting airway and lungs. ${ }^{32}$ This is accomplished by a large surface area that interacts with inspiratory and expiratory gases. Exposing the nasopharyn- 
geal tissues to dry cool gas at greater than normal minute ventilation stresses the upper airway. Often, children who require oxygen therapy are experiencing respiratory distress with an increased minute ventilation and suffer from some form of dehydration. Providing dry oxygen may treat their hypoxemia but set them up for other complications. Historically, in pediatrics, we have applied inexpensive bubble humidifiers to low-flow oxygen delivery devices in an attempt to add water content to the gas delivered. However, this may not adequately hydrate the gas. It is a standard of care in pediatrics to heat and humidify gases delivered from a mechanical ventilator. ${ }^{33}$ More recently, there has been a growing interest in and use of high-flow nasal cannula (HFNC) that enables the heating and humidification of oxygen through the traditional nasal cannula interface. See the included discussion on HFNC in the present article.

There are also risks from oxygen's potential to support combustion, since it is an oxidizer. This was a particular issue when we used large oxygen tents and children would bring spark-emitting toys within the oxygen-rich environment. Today, most no longer use such devices.

\section{Physiologic Effects of Oxygen Therapy}

Despite its universal acceptance as a life-saving therapy for children, oxygen administration is associated with numerous physiologic effects.

\section{Reversing Hypoxemia}

Whereas oxygen therapy is generally titrated to some measure of arterial oxygenation in response to an abnormally low level of blood oxygen (hypoxemia), oxygen is administered to reverse (return to normoxia) or prevent hypoxia. Individual responses to oxygen therapy vary greatly, depending on the particular cause of hypoxia and the degree of impairment. Hypoxia caused by hypoventilation and ventilation/perfusion anomalies associated with pulmonary disease will be most responsive to oxygen therapy. Even large increases in $\mathrm{F}_{\mathrm{IO}_{2}}$ will produce only small increases in available oxygen if hypoxia is caused by cardiac shunts, shock, or hemoglobin deficiency/dysfunction. ${ }^{23,24}$ It should be stressed, however, that even small increases in oxygen availability may prevent life-threatening decompensation in the hypoxic child.

\section{Permissive Hypoxemia}

The American Academy of Pediatrics in 2006 first recommended a permissive hypoxemic $\mathrm{S}_{\mathrm{pO}_{2}}$ target $\geq 90 \%$ strategy for infants suffering from bronchiolitis ${ }^{34}$ and later reinforced this practice in their clinical practice guideline of the diagnosis, management, and prevention of bronchioli- tis in 2014. ${ }^{35}$ Less aggressive management of hypoxemia has been proposed to be safe in diseases in which the course progression is predictable, such as bronchiolitis. Cunningham et $\mathrm{al}^{36}$ conducted a double-blind, randomized, equivalence trial and concluded that management of infants with a $\mathrm{S}_{\mathrm{pO}_{2}}$ target of $\geq 90 \%$ is as safe and clinically effective as management with a $\mathrm{S}_{\mathrm{pO}_{2}}$ of $\geq 94 \%$. The intent is to use a lower threshold to be able to discontinue oxygen therapy more quickly and hopefully discharge patients sooner, reducing cost of care. However, future research is needed to enable translation of these findings to older children.

Another form of permissive hypoxemia used in critically ill children suggested to be lung-protective aims to provide a patient with severe disease (often mechanically ventilated) a level of oxygen delivery adequate to avoid hypoxia while minimizing the detrimental effect of a toxic level of oxygen or toxic ventilator support. ${ }^{37}$ This form of permissive hypoxemia aims for a lower $\mathrm{S}_{\mathrm{pO}_{2}}$ of approximately $82-88 \%$ and serves to balance between toxic effects of high ventilator settings and oxygen concentrations. Permissive hypoxemia is often considered after aggressive ventilation strategies have been explored. A Cochrane review could not confirm or disprove the benefits of permissive hypoxemia. ${ }^{38}$ Some consider the benefits received from permissive hypoxemia as stemming from the reduction in hyperoxia. ${ }^{39}$

\section{Duration of Hypoxemia}

Recording duration of hypoxemia can be a difficult task because many of our patients may be hypoxemic long before we assess them. Even within our hospital environment, none of our monitors record duration of hypoxemia (ie, minutes below low alarm over the course of a hospital stay). Once hypoxemia is identified, we often want to return the patient to normoxia. If the hypoxemia is sudden, this might be the proper course of action; however, in critical illness, a reliance on aggressively high oxygen concentrations to maintain normoxia may risk inadvertently causing damage or impeding the adaptive response. ${ }^{40}$ Martin and Grocott ${ }^{39}$ took the traditional definition of hypoxemia a step further by proposing terms based on physiologic response to the duration of its development. The time course of hypoxemia may influence decisions to implement a permissive hypoxemic, normoxia, or supranormal cardiac output ${ }^{37}$ (to compensate for low oxygen content) strategy. Table 2 describes the categorization proposed by Martin and Grocott ${ }^{39}$, which we have modified for pediatric consideration.

\section{Oxygen Toxicity}

The detrimental effects of oxygen therapy were first recognized in the late 19th century by Paul Bert, ${ }^{41}$ using 
Table 2. Hypoxemia Categorized by Duration

\begin{tabular}{ll}
\hline \hline $\begin{array}{c}\text { Types of } \\
\text { Hypoxemia }\end{array}$ & \multicolumn{1}{c}{ Description } \\
\hline Acute & Rapid onset, usually $<6 \mathrm{~h}$ (eg, upper-airway obstruction) \\
Subacute & Occurring for $6 \mathrm{~h}$ to $7 \mathrm{~d} \mathrm{(eg,} \mathrm{pneumonia)}$ \\
Sustained & Occurring for $7-90 \mathrm{~d}(\mathrm{eg}$, prolonged pediatric ARDS) \\
Chronic & Occurring for $>90 \mathrm{~d}$ (eg, CHD or BPD) \\
Generational & Cross-generational (eg, Tibetan highland residents) \\
\hline $\mathrm{CHD}=$ congenital heart disease \\
$\mathrm{BPD}=$ bronchopulmonary dysplasia
\end{tabular}

hyperbaric oxygen systems. It has been known for years that breathing an $\mathrm{F}_{\mathrm{DO}_{2}}$ of 1.0 for as little as $3 \mathrm{~h}$ can start to cause chest pain, with longer periods leading to signs similar to bronchopneumonia. Exposure to high concentrations of oxygen first damages the capillary endothelium, followed by interstitial edema $(0-12 \mathrm{~h})$, worsening compliance and vital capacity (12-30 h), followed by thickening of the alveolar-capillary membrane $(30-72 \mathrm{~h}) .{ }^{20}$ If the process continues, type I alveolar cells are destroyed, and type II cells proliferate. An exudative phase follows, resulting in a low ventilation/perfusion ratio, physiologic shunting, and worsening hypoxemia. ${ }^{42}$

$\mathrm{F}_{\mathrm{IO}_{2}}>0.50$ presents a significant risk of absorption atelectasis. ${ }^{43}$ Breathing high levels of oxygen quickly depletes body nitrogen levels. As blood nitrogen levels decrease, the total pressure of venous gases rapidly decreases. Under these conditions, gases that exist at atmospheric pressure within the alveoli rapidly diffuse into the venous blood, and collapse occurs. The risk of absorption atelectasis may be greatest in children breathing at low tidal volumes.

More recently, it has become clear that high concentrations of normobaric oxygen may also be harmful. As the gas exchange interface to the body, it is logical that the lung would have one of the greatest risks of damage. This injury has been demonstrated in numerous studies of animals and healthy human volunteers. ${ }^{44}$ This injury has been related to the type of injury seen in ARDS. ${ }^{45}$ The magnitude of injury appears to be directly related to the concentration of oxygen and duration of treatment. ${ }^{2}$

\section{Oxidative Stress}

The role of oxygen and oxidative stress has generated much interest. Oxidative stress has been defined as an imbalance between pro- and anti-oxidant forces in the body. ${ }^{46}$ Pro-oxidants include oxygen radicals or reactive oxygen species (ROS), which can be cytotoxic due to their ability to alter cellular components and function. ROS are generated in the environment and as a result of normal mitochondrial respiration but also during the reperfusion phase of hypoxic tissue injury and in association with infection and inflammation. ${ }^{47,48}$ Oxygen is "toxic" because of the production of ROS; thus, oxygen administration increases oxidative stress. The biochemical basis for the effects of hyperoxia is the formation of oxygenfree radicals. Oxygen-free radicals have one or more unpaired electrons, a combination that makes them very unstable. ${ }^{49}$ ROS such as hydroxyl ion and peroxynitrite interact with lipids, DNA, and proteins via oxidative reactions or radical-mediated mechanisms. ${ }^{50}$ These reactions trigger a host of responses ranging from modulations of cell signaling to overwhelming oxidative injury, necrosis, or apoptosis.

Antioxidant defenses include the enzymes superoxide dismutase, catalase, and glutathione. Nonenzymatic oxidants start to cross the placenta in late gestation and include vitamins $\mathrm{A}, \mathrm{C}$, and $\mathrm{E}$ and ubiquinone. Premature infants are at particular risk from oxidative stress because both endogenous and passively acquired exogenous antioxidant defense systems do not accelerate in maturation until late in the third trimester. ${ }^{47,51,52}$ Investigators have attempted to reverse or prevent the damage associated with ROS not only by appropriate oxygen administration but also by administering antioxidants; however, this therapy has not shown to be effective. ${ }^{53}$ Saugstad $^{54}$ has suggested the term oxygen radical disease of neonatology to encompass a variety of newborn diseases whose pathogenesis involves oxidative stress and injury, which include retinopathy of prematurity, bronchopulmonary dysplasia (BPD), necrotizing enterocolitis, and intraventricular hemorrhage. The body has many antioxidant systems to combat such an offense, but these are often defeated by high concentrations of oxygen, typically $>50 \%$. High $\mathrm{F}_{\mathrm{IO}_{2}}$ overpowers the antioxidant system's capacity to prevent or repair. It is important to note that lower levels of $\mathrm{F}_{\mathrm{IO}_{2}}(0.25-0.5)$ may do just as much damage in patients with impaired or stressed antioxidant systems (premature neonates, malnourishment, etc). Figure 2 describes the theoretical general risk of oxygen toxicity by concentration and time.

\section{Hyperoxia}

There is a growing body of literature that points to the potential harm associated with using high concentrations of inspired oxygen. Hyperoxia has been defined by the use of oxygen therapy to create an $\mathrm{P}_{\mathrm{aO}_{2}}$ greater than normal. Most define this as a $\mathrm{P}_{\mathrm{aO}_{2}}$ of $120-150 \mathrm{~mm} \mathrm{Hg}$ or higher, 55,56 whereas others have assumed hyperoxia by the indiscriminate use of high oxygen concentrations for a variety of conditions in which hypoxia is suspected (eg, trauma, chest pain, shortness of breath). 


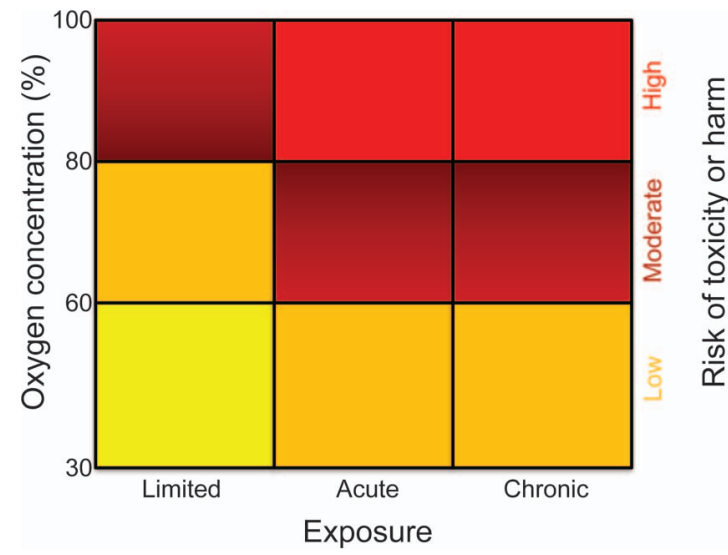

Fig. 2. Theoretical heat map of potential risk of toxicity by oxygen concentration and exposure.

Cardiovascular System. Presumed hyperoxia associated with routine treatment with oxygen therapy during myocardia infarct has been associated with no benefit ${ }^{57}$ and in fact may be harmful, resulting in a greater infarct size and increasing mortality. ${ }^{58}$ The group of Siv Fonnes ${ }^{59}$ in Denmark found subjects undergoing abdominal surgery who were exposed to 0.8 versus $0.3 \mathrm{~F}_{\mathrm{IO}_{2}}$ intra-operatively and postoperatively had an increased long-term risk of myocardial infarction and other heart disease.

In pediatrics, we often see patients with cyanotic congenital heart disease who are chronically hypoxemic and require surgery. A cardiopulmonary bypass machine is used to facilitate surgery. Cardiopulmonary bypass, if not controlled, exposes patients to high levels of oxygen that they have not experienced before. This reoxygenation injury can lead to significant organ damage, including myocardium, and trigger a systemic inflammatory response. ${ }^{60-63}$ Caputo et $\mathrm{al}^{64}$ provided direct evidence that controlling reoxygenation in cyanotic heart disease subjects reduced biomarkers of inflammation, stress, myocardial, cerebral, and hepatic injury.

Central Nervous System. Central nervous system toxicity has been found in the form of seizures and usually starts with visual changes (tunnel vision) and then progresses to tinnitus, nausea, facial twitching, dizziness, and confusion. ${ }^{49}$ This toxicity is well-documented and has only been found in hyperbaric oxygen therapy. To control these adverse events, duration of hyperbaric oxygen therapy is limited, with oxygen breaks that are strictly adhered to. An oxygen break is defined as a decrease in the amount of inspired oxygen, usually room air.

Normobaric hyperoxia in traumatic brain injury may be therapeutic. Vilalta et al ${ }^{65}$ in Spain found that normobaric hyperoxia (100\% oxygen) for $2 \mathrm{~h}$ in subjects with high brain lactate improved the brain's redox state. Although no other outcomes were studied, short courses of hyperoxia in the right patient may improve outcome. Further research is needed in pediatrics to balance the other plausible effects of high concentrations of oxygen on the overall outcome in those with severe traumatic brain injury.

During Resuscitation. Survival to hospital discharge after in-hospital and out-of-hospital cardiac arrest remains low. ${ }^{66,67}$ Even with the return of spontaneous circulation, many children die in subsequent days, with death usually attributed to neurological injury or cardiovascular dysfunction. ${ }^{67}$ Supplemental oxygen therapy remains central to care during and following resuscitation. An association between hypoxia and poor outcome after cardiac arrest has long been accepted.

Infants. Concerns about potentially detrimental effects of hyperoxia have been raised in the neonatal resuscitation with reports demonstrating worse long-term outcomes with higher $\mathrm{F}_{\mathrm{IO}_{2}}$ leading to higher $\mathrm{S}_{\mathrm{pO}_{2}}$ during resuscitation. 68,69 The use of $100 \%$ oxygen during neonatal resuscitation has also been challenged on the premise that large and abrupt increases in blood oxygen levels after birth can increase oxidative stress. ${ }^{54}$ Several studies have compared the use of $21 \%$ with the use of $100 \%$ oxygen during resuscitation. Three meta-analyses of these data concluded that the use of room air during the resuscitation of depressed newborns resulted in a significantly reduced risk of neonatal mortality. ${ }^{69-71}$ The studies found no significant difference in the incidence of severe hypoxic encephalopathy between the $21 \%$ oxygen and $100 \%$ oxygen groups. In one small study, the resuscitation of premature newborns with $50 \%$ versus $100 \%$ oxygen did not reduce the incidence of BPD or improve other short-term outcomes. ${ }^{72}$ This may indicate that the dose may be an important factor to produce improved outcomes. Related to the use of oxygen in the delivery room for resuscitation, limited evidence suggests that the exposure of newborns to oxygen for $3 \mathrm{~min}$ or longer immediately after birth increases the risk of childhood cancer. ${ }^{73,74}$ This led the American Heart Association to recommend beginning resuscitation with room air for the term infant or blended oxygen for preterm infants with subsequent titration of $\mathrm{F}_{\mathrm{IO}_{2}}$ to acceptable $\mathrm{S}_{\mathrm{pO}_{2}}$ values. ${ }^{75}$

Children. Despite guidelines that advocate maintenance of normoxia and normoventilation after pediatric cardiac arrest, this is uncommonly achieved in practice. ${ }^{76}$ The fact that this is rarely achieved has limited the ability of investigators to draw conclusions. Ferguson et al $^{77}$ demonstrated that hypoxia and to a lesser extent, and hyperoxia were associated with an increased risk of death after pediatric ICU admission for cardiac arrest. Preclinical data suggesting potential harm with hyperoxia remain compelling despite the lack of evidence, but hypoxia also cannot be ignored. Similarly, some adult studies link hyperoxia with 
poorer outcomes, ${ }^{78,79}$ although others refute this. ${ }^{80}$ Despite the lack of evidence in children, the American Heart Association recommends initial resuscitation efforts with $100 \%$ oxygen followed by titration of oxygen to achieve an $\mathrm{S}_{\mathrm{pO}_{2}}$ of $\geq 94 \% .81,82$

\section{Oxygen Delivery Devices}

When selecting oxygen delivery devices, it is helpful to keep in mind the acronym AIM, which stands for assessment of patient need, identification of technological capabilities, and matching technology with need. Following is a breakdown of the most routinely used devices in pediatric respiratory care.

\section{Blow-by Oxygen}

Blow-by oxygen delivery is the simplest and least cumbersome form of available devices to provide oxygen therapy, but it is also the least reliable at delivering a specific $\mathrm{F}_{\mathrm{IO}_{2}}$. Blow-by oxygen can be achieved in numerous ways, but it is most commonly done by means of large bore or oxygen tubing connected to a face tent or a simple mask that is placed a relatively short distance from, and directed toward, the patient's face. This type of oxygen delivery is ideal for patients who cannot tolerate more cumbersome oxygen delivery devices and/or require a lower concentration of oxygen. There is limited evidence that suggests that blow-by therapy can deliver low concentrations of oxygen (0.3-0.4 at $10 \mathrm{~L} / \mathrm{min}$ of flow) to an area large enough to provide some level of oxygen therapy, assuming adequate positioning of the device. ${ }^{83}$ Therefore, this type of therapy should be reserved for those who do not require high inspired oxygen concentrations but may require short-term or intermittent oxygen therapy.

\section{Oxygen Hood or Tent}

An oxyhood (cube) or tent is a plastic enclosure that surrounds the head of the neonate or the body of an older child, to which a continuous flow of humidified oxygen is supplied by means of an air entrainment device or an air-oxygen blender. Fixed oxygen concentrations from 22 to $80 \%$ can be maintained with a minimum of $7-10 \mathrm{~L} / \mathrm{min}$ oxygen flow into the hood and $15-30 \mathrm{~L} / \mathrm{min}$ within a tent. This minimum gas flow also ensures that exhaled carbon dioxide is flushed out and not rebreathed. Although these devices can theoretically deliver $\mathrm{F}_{\mathrm{IO}_{2}}>0.5$, these devices are best suited for patients who require $<0.5 \mathrm{~F}_{\mathrm{IO}_{2}}$. Patients requiring higher $\mathrm{F}_{\mathrm{IO}_{2}}$ can be managed in a hood or tent, but it becomes increasingly difficult to maintain higher oxygen concentrations with the large neck opening and a less than optimal seal around the edges. ${ }^{84-86}$ Neither device is utilized frequently because nasal cannula has become the mainstay for low $\mathrm{F}_{\mathrm{DO}_{2}}$. When a higher $\mathrm{F}_{\mathrm{DO}_{2}}$ is required, oxygen therapy via a noninvasive or invasive ventilation is typically the next logical step.

\section{Low-Flow Nasal Cannula}

Low-flow nasal cannula remains one of the most common and widely used oxygen delivery devices. This lowflow device delivers a fractional concentration of oxygen to the patient through 2 soft prongs that rest in the patient's anterior nares. The cannula tubing is then attached to either a $100 \%$ oxygen source flow meter or to an air-oxygen blender. Finer et al ${ }^{87}$ found that oxygen concentrations delivered to the neonate via nasal cannula varied from 22 to $95 \%$ with a maximum flow of $2 \mathrm{~L} / \mathrm{min}$. The precise $\mathrm{F}_{\mathrm{IO}_{2}}$ actually delivered to the patient is contingent upon a number of factors, but most specifically the set flow through the nasal cannula and its relation to the patient's inspiratory flow demand. It is important not to occlude the naris to allow for room air entrainment and to avoid inadvertently providing positive expiratory pressure. An inspiratory flow demand greater than that supplied by the nasal cannula causes the exact $\mathrm{F}_{\mathrm{IO}_{2}}$ delivered to the patient to be a blend of the nasally inhaled oxygen with entrained room air through the nares and mouth. ${ }^{14,84,87}$ A nasal cannula should not be used in a patient with blocked nasal passages. Whereas actual oxygen concentrations delivered to the patient are variable, a nasal cannula remains a fairly trusted and effective method of offering oxygen therapy to the neonate.

\section{High-Flow Nasal Cannula}

Nasal cannula oxygen therapy is a staple and continues to be redefined to improve patient comfort, compliance, and outcomes. The concept of high flow and high humidity via a nasal cannula (high-flow nasal cannula; HFNC), however, is an evolving concept. HFNC is a form of oxygen therapy and support used to treat hypoxemic respiratory failure. Before HFNC, most clinicians considered it uncomfortable to use a flow of $>1 \mathrm{~L} / \mathrm{min}$ via nasal cannula for newborns ${ }^{88,89}$ and $>2 \mathrm{~L} / \mathrm{min}$ in older children ${ }^{84}$; this was primarily due to the lack of adequate humidification available via nasal cannula delivery. Little consensus existed in the pediatric patient population on the parameters defining HFNC, but for our discussion, HFNC is classified as a fixed-performance oxygen delivery system that is capable of delivering a specific oxygen concentration at flows that meet or exceed the inspiratory flow demand of the patient. ${ }^{84}$ This type of oxygen delivery device is composed of traditional nasal cannula style prongs that rest in the patient's anterior nares and allow heated, humidified oxygen to be delivered at flows of $2-8 \mathrm{~L} / \mathrm{min}$ for neonates and 4-70 L/min for children, whereas an 


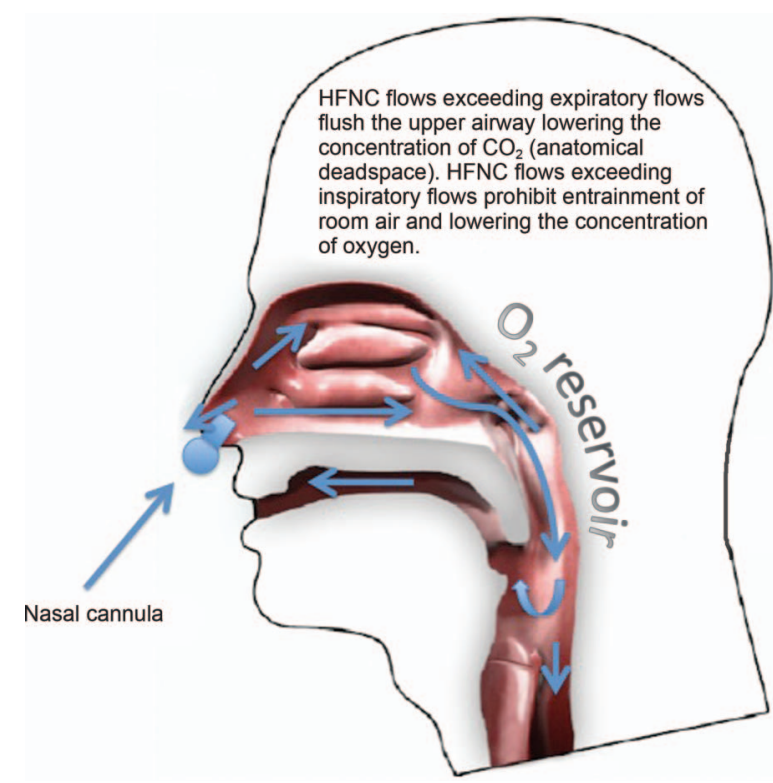

Fig. 3. Cross-sectional view of a patient's upper airway. Arrows describe the filling of the oxygen reservoir and washing out of the extrathoracic dead space by flows that exceed patient demand. From Reference 91.

air-oxygen blender allows $\mathrm{F}_{\mathrm{IO}_{2}}$ to be directly manipulated..$^{90}$ As higher flows are reached, set oxygen flows exceed demand, thus preventing the entrainment of room air, flushing dead space (Fig. 3), ${ }^{91}$ and affecting the delivery of higher, more precise fractional inspired oxygen concentrations.

High-flow nasal cannula use has been adopted in many institutions for its ease of use and patient tolerance but also for its ability to provide higher oxygen concentrations and inspiratory flows, thus providing a higher level of oxygenation support than can rarely be achieved by any of the other devices described above. Debate is ongoing as to whether HFNC may reduce the use of less tolerated and more invasive ventilator support, such as CPAP and mechanical ventilation. Table 3 describes typical starting flows as a guide when starting HFNC. ${ }^{22}$ These starting flows are based in estimated inspiratory flows. The assumption is based on the understanding that if you provide higher than inspiratory flows, (1) you will prohibit room air entrainment and (2) you will exceed expiratory flows and washout dead space at the end of expiration. Certainly, more or less can be provided based on the patient size, disease, and needs.

Improvements in oxygenation associated with HFNC may also be related to the creation of PEEP in certain patient populations for a given flow. HFNC has been shown to significantly increase esophageal pressure ${ }^{92,93}$ and pharyngeal pressure ${ }^{94}$ in neonates. Locke et $\mathrm{al}^{93}$ demonstrated that in a group of premature infants, the amount of generated positive pressure varied not only with flow but with
Table 3. Initial or Starting Flows of High-Flow Nasal Cannula in a Pediatric Population by Age

\begin{tabular}{llc}
\hline \hline \multicolumn{1}{c}{ Age } & Weight $(\mathrm{kg})$ & $\begin{array}{c}\text { Starting Flow } \\
\text { (L/min) }\end{array}$ \\
\hline$<30 \mathrm{~d}$ & $3-5$ & 0.6 \\
1 month to $1 \mathrm{y}$ & 5 to $<10$ & 0.5 \\
$1-7$ y & 10 to $<27$ & 0.4 \\
$8-14$ y & 20 to $<40$ & 0.3 \\
$>14$ y & $\geq 40$ & 0.2
\end{tabular}

These initial flows are based on the estimated lowest inspiratory flows during mild respiratory disease.

cannula size; the larger cannula size produced a mean pressure of $9.8 \mathrm{~cm} \mathrm{H}_{2} \mathrm{O}$ at a flow of $2 \mathrm{~L} / \mathrm{min}$. Although HFNC use has skyrocketed particularly in infants and young children hospitalized with bronchiolitis, evidence supporting its use is relatively lacking, as underscored in $2 \mathrm{Co}-$ chrane reviews. ${ }^{95,96}$ Evidence to date suggests that HFNC is safe, with a relatively low complication rate, ${ }^{97}$ and that it is a well-tolerated and a feasible method for delivering oxygen to infants and young children ${ }^{98}$ with a wide variety of respiratory distress, work of breathing, and levels of hypoxemia. In fact, HFNC has been proposed to be more cost-effective in the treatment of bronchiolitis than standard treatments. When using HFNC in moderate to severe respiratory distress, about one quarter of cases will require escalation to another form of respiratory support. ${ }^{99}$ Through mechanisms of extrathoracic dead space washout, increasing pulmonary compliance plausibly from distending pressure or humidification, it has been suggested that HFNC can reduce work of breathing ${ }^{100}$ and decrease the need of escalation of therapy to CPAP or invasive ventilation..$^{98}$

\section{Oxygen Mask}

Since the development of the oxygen tent, smaller versions of variable-performance oxygen delivery systems have been developed. There are pediatric versions of simple, air-entrainment, and reservoir masks that have been used safely for years. These oxygen delivery systems are often selected as short-term solutions to hypoxemic events, such as postoperative period (mostly the simple mask and air-entrainment aerosol masks) or emergency (reservoir mask). The air-entrainment type of devices can be coupled with cool or heated aerosol, depending on the need.

Oxygen masks are often difficult to keep secured on vigorous children and require the change out of systems or adapters if a change in $\mathrm{F}_{\mathrm{DO}_{2}}$ is desired. In a pediatric facility, it can be difficult to stock multiple sizes and types, not to mention the disruption in the patient's care. Recently, there has been an advancement in technology that helps reduce one of these variables, $\mathrm{F}_{\mathrm{DO}_{2}}$. The Oxymask 
Table 4. Types of Oxygen Delivery Device, $\mathrm{F}_{\mathrm{DO}_{2}}$ Capabilities, and Indications for Use

\begin{tabular}{|c|c|c|c|c|}
\hline System & $\mathrm{F}_{\mathrm{DO}_{2}}$ & Design & Indications & Comments \\
\hline Blow-by & $<0.30$ & Low-flow, variable & $\begin{array}{l}\text { Low dose and patient does not } \\
\text { tolerate mask }\end{array}$ & $\begin{array}{l}\text { Inconsistent delivery and must } \\
\text { monitor } \mathrm{S}_{\mathrm{pO}_{2}}\end{array}$ \\
\hline Nasal cannula ( $\leq 6 \mathrm{~L} / \mathrm{min})$ & $0.25-0.40$ & Low-flow, variable & Low dose & $\begin{array}{l}\text { Affected by changes in inspiratory } \\
\text { flow }\end{array}$ \\
\hline HFNC (1-70 L/min) & $0.21-1.00$ & $\begin{array}{l}\text { Can be high- or low-flow and } \\
\text { variable or fixed }\end{array}$ & Low to high doses & \multirow{2}{*}{$\begin{array}{l}\text { Affected by changes in inspiratory } \\
\text { and expiratory flow; requires } \\
\text { heat and humidification }\end{array}$} \\
\hline Simple mask & $0.35-0.50$ & Low-flow, variable & & \\
\hline Partial rebreather mask & $0.50-0.60$ & Low-flow, reservoir, variable & $\begin{array}{l}\text { Moderate dose used to } \\
\text { conserve oxygen }\end{array}$ & Must tolerate a mask \\
\hline Non-rebreather mask & $0.65-0.95$ & Low-flow, reservoir, fixed & High dose & $\begin{array}{l}\text { Tight fit required to obtain higher } \\
\text { concentrations and must tolerate } \\
\text { a mask }\end{array}$ \\
\hline Oxymask & $0.24-0.90$ & $\begin{array}{l}\text { High- and low-flow, variable } \\
\text { and fixed }\end{array}$ & Low to high dose & $\begin{array}{l}\text { Requires proper positioning of the } \\
\text { diffuser and patient must be } \\
\text { able to tolerate a mask }\end{array}$ \\
\hline Hood or Tent & $\begin{array}{c}0.25-0.90 \text { (hood) } \\
0.25-0.50 \text { (tent) }\end{array}$ & $\begin{array}{l}\text { High-flow enclosure, fixed } \\
\text { (oxyhood)/variable (tent) }\end{array}$ & Low to high doses & $\begin{array}{l}\text { Imprecise dosing of oxygen, heat } \\
\text { and humidity }\end{array}$ \\
\hline Manual resuscitators & $0.21-1.00$ & Reservoir, fixed & $\begin{array}{l}\text { Low to high doses when } \\
\text { mechanical support is } \\
\text { required }\end{array}$ & $\begin{array}{l}\text { May require a blender or a } \\
\text { reservoir to deliver required } \\
\text { dosing }\end{array}$ \\
\hline Mechanical ventilators & $0.21-1.00$ & High flow, fixed & $\begin{array}{l}\text { Low to high doses when } \\
\text { mechanical support is } \\
\text { required }\end{array}$ & $\begin{array}{l}\text { Some subacute care and } \\
\text { noninvasive devices cannot } \\
\text { provide high-dose oxygen }\end{array}$ \\
\hline $\begin{array}{l}\mathrm{HFNC}=\text { high-flow nasal cannula } \\
\mathrm{F}_{\mathrm{DO}_{2}}=\text { fraction of delivered oxygen } \\
\mathrm{S}_{\mathrm{pO}_{2}}=\text { oxygen saturation }\end{array}$ & & & & \\
\hline
\end{tabular}

(Southmedic, Barrie, Canada) has been developed as a mask for pediatrics and adults that can deliver 0.24-0.9 $\mathrm{F}_{\mathrm{IO}_{2}}$ by the use of a diffuser that the mask serves to hold just outside and between the nose and mouth. ${ }^{101-103}$ This wide range of dosing allows the use of one mask for mild to severely hypoxemic patients. See Table 4 for a breakdown of the systems available and $\mathrm{F}_{\mathrm{DO}_{2}}$ ranges that they can provide.

\section{Mechanical Ventilation}

Mechanical ventilation is often used to deliver oxygen therapy and treat moderate to severe hypoxemia. Current clinical teaching emphasizes the avoidance of hypoxemia during mechanical ventilation. Some of the benefits of reversing hypoxemia may be outweighed by the harms associated with high concentrations of oxygen while providing mechanical ventilation. However, many critically ill patients who receive mechanical ventilation demonstrate a persistently low $\mathrm{S}_{\mathrm{pO}_{2}}$ despite our best efforts to resolve it. Efforts, which include high levels of $\mathrm{F}_{\mathrm{IO}_{2}}$, PEEP, and plateau pressures to restore normoxia, may be more harmful than the acceptance of a degree of hypoxemia, which highlights the potential clinical benefit of permissive hypoxemic mechanical ventilation strategies. But the balance of risk and harm at differing oxygen concentrations and mechanical ventilation support is not well defined. ${ }^{39}$ The safe lower limit of $\mathrm{S}_{\mathrm{pO}_{2}}$ in critical pediatric patients is unknown. High $\mathrm{F}_{\mathrm{IO}_{2}}$ causes pulmonary damage, but safety thresholds are also not known. Practitioners who are able to reduce hypoxemia without creating hyperoxia or hyperventilation will probably have better patient outcomes.

\section{Monitoring of Oxygen Therapy}

Following the assessment of need as previously discussed, a planned desired physiologic outcome and the adequacy of the patient's response to therapy should be monitored. With this plan comes an assessment tool or monitors of success. Most use a noninvasive monitoring strategy like pulse oximetry or arterial blood gases for the acid/base balance (indicator of hypoxia leading to a metabolic acidosis) or $\mathrm{P}_{\mathrm{aO}}$ to assist with their clinical assessment. Venous or capillary blood gases are not used to evaluate oxygenation. Assessment frequency should be based on the severity of hypoxemia (eg, level of $\mathrm{F}_{\mathrm{IO}_{2}}$ required), overall severity of illness, or variability of oxygen delivery device. 
Before pulse oximetry, it was a fairly easy assessment: You were either pink or blue, which typically corresponded with a $\mathrm{S}_{\mathrm{pO}_{2}}$ of around $80-85 \%$. Alternatively, intermittent invasive arterial blood samples were used to determine $\mathrm{pH}, \mathrm{P}_{\mathrm{aCO}}$, and $\mathrm{P}_{\mathrm{aO}_{2}}$. Second, you would also clinically assess the patient's work of breathing or improvement in distress following oxygen administration. The introduction of pulse oximetry in clinical practice has allowed for a simple, noninvasive, and reasonably accurate estimation of arterial oxygen saturation. Now pulse oximetry is almost exclusively used to monitor and treat hypoxemia, no matter the environment or setting. Safe use of pulse oximetry requires knowledge of its limitations, which include motion artifacts, poor perfusion, irregular rhythms, ambient light, calibration assumptions, probe positioning, built-in signal process or alarm delays, venous pulsation, intravenous dyes, or the presence of dyshemoglobins, not to mention that $\mathrm{S}_{\mathrm{pO}_{2}}$ cannot determine hyperoxia and its associated complications. Clinically relevant principles and inherent limitations of the method used to determine the arterial oxygen saturation are not always understood or considered by clinicians. If $\mathrm{S}_{\mathrm{pO}_{2}}$ levels are $>88-90 \%$ and the patient remains in distress, you must assess other measures of oxygen delivery despite a reassuring $\mathrm{S}_{\mathrm{pO}_{2}}$ level. The potential for overtreatment of hypoxemic events is of particular interest, since it may be associated with an increased length of stay and cost of care, but further work is needed to determine the specific association.

The utility of continuous pulse oximetry outside of the critical care environment and operating room has become controversial. In 2004, Schroeder et al ${ }^{104}$ determined that the stay for hospitalized infants with bronchiolitis may have been prolonged by the perceived need for supplemental oxygen therapy based on oximetry readings. The work of Schroeder et al ${ }^{104}$ and others led to the development of a wonderful publication titled Choosing Wisely in Pediatric Hospital Medicine: Five Opportunities for Improved Healthcare Value. ${ }^{105}$ This group reached several conclusions related to oxygen therapy and monitoring: (1) continuous $\mathrm{S}_{\mathrm{pO}_{2}}$ monitoring in bronchiolitis in the acute care environment may led to overdiagnosis of hypoxemia and subsequent oxygen use; (2) lowering the treatment threshold from an $\mathrm{S}_{\mathrm{pO}_{2}}$ of $94 \%$ to $90 \%$ saves $22 \mathrm{~h}$ of hospitalization; and (3) as a child's clinical course improves, continuous measurement of $\mathrm{S}_{\mathrm{pO}_{2}}$ is not routinely needed (also the recommendation of the American Academy of Pediatrics). Since their publication, McCulloh et $\mathrm{al}^{106}$ have conducted a randomized controlled trial examining the use of intermittent versus continuous pulse oximetry for nonhypoxemic infants and young children hospitalized for bronchiolitis and found that the use of intermittent pulse oximetry did not shorten stay and was not associated with any difference in the rate of escalation of care or use in diagnostic or therapeutic measures. Al- though this did not answer the question of whether this can be done in the hypoxemic patient treated with oxygen therapy, it does lay the groundwork for future study.

\section{Other Considerations}

Often when oxygen is prescribed or applied in pediatrics, we rarely assess the implications of our therapies for the caregivers outside of the clinic or hospital. It is conceivable that taking care of a complex child at home can generate apprehension and anxiety in parents. Zanardo and Freato $^{7}$ assessed the anxiety of parents of infants with BPD and found that those whose children were in the oxygen-dependent group were at an increased risk to have pre-discharge anxiety. This anxiety improves with respiratory status and subsequent cessation of oxygen therapy. Clinicians should pay special attention to the emotional needs of parents/caregivers of those children discharged receiving oxygen therapy.

\section{Home Environment}

Oxygen therapy within the home environment can cause some issues if not properly managed. Although oxygen is neither combustible nor explosive, it does support combustion and could encourage a fire to spread more quickly, especially in a fuel-rich environment. Fuel is considered to be anything combustible. For example, one that we often struggle with is the use of petroleum jelly on the lips or nose of our patients who wear oxygen. Oil-based products can be a fuel source and have been known to burn with explosive violence if ignited in the presence of oxygen. Attempts to reduce fuel stores are advisable. It is important for those on oxygen therapy to be away from open flames and heat sources to minimize direct interaction.

In addition to being a fire hazard, oxygen tubing can be a trip hazard. Not only can tubing harm the individual who trips, but it can also pull the child in the direction of the trip and dislodge the oxygen system, creating another hazard or damaging the equipment. Oxygen systems should be properly secured, and oxygen tubing should be off of the floor to minimize this hazard.

\section{Preparation of Oxygen}

The 2 most commonly used methods to prepare oxygen are fractional distillation of liquid air and the physical separation of atmospheric air. Fractional distillation of liquid air relies on the Joule-Kelvin effect, where air is filtered, and water vapor is removed and cooled in stages until it reaches $-200^{\circ} \mathrm{C}$. At each stage of cooling, a liquid is removed. For example, carbon dioxide freezes at $-79^{\circ} \mathrm{C}$, oxygen liquefies at $-183^{\circ} \mathrm{C}$, and nitrogen liquefies at $-196^{\circ} \mathrm{C}$. At each stage of cooling, the liquid is re- 
moved. This is repeated until what remains is pure oxygen with no toxic impurities. It is then transferred to cryogenic storage cylinders for distribution as a liquid or conversion to a gas following condensing and placed in high-pressure cylinders. Liquid oxygen reservoir systems, often referred to as bulk oxygen systems, are used for small and large health-care facilities to provide 50-psi oxygen to the patients' bedside. Gas supply companies also use liquid oxygen to provide oxygen gas to pressurized tanks of all sizes.

The second method is physical separation or concentration of the oxygen. These oxygen concentrators are often used to supply low-flow oxygen in the home environment. There are 2 types of physical separation systems. One uses molecular sieves compounded of inorganic sodium aluminum silicate pellets. These pellets absorb nitrogen, traces gases, and water vapor from the air, providing $>90 \%$ oxygen for patient use. The second uses a vacuum to pull ambient air through a semipermeable plastic membrane. The membrane allows oxygen and water vapor to pass through at a faster rate than does nitrogen. This system can provide an oxygen mixture of approximately $40 \%$.

\section{Portable Options}

There are several portable options for oxygen therapy. It is important to provide portable options to patients who require oxygen for emergency purposes but also for daily activities of living. The therapeutic goal of oxygen therapy is to be able to return the patient to normal activities. Oxygen therapy should not trap a patient within the home. There are the traditional small high-pressure cylinders that have been successfully used for years. Tanks of oxygen have been the most efficient portable system for pediatrics; however, they require resupplying by a medical gas company. Small portable liquid oxygen systems have been available for years but are the least cost-efficient system because they require a liquid oxygen reservoir recharging station. Additionally, the liquid oxygen system must be allowed to expand, which wastes oxygen when not in use. Recent advances have allowed for the miniaturization of oxygen concentrators that can be carried around. The limitation to these devices is the battery life.

\section{Oxygen-Conserving Devices}

Oxygen-conserving devices control the flow of oxygen from the source to the patients. Most oxygen systems deliver oxygen continuously. An oxygen-conserving device only provides oxygen when the patient inspires, thus dramatically reducing waste while providing the same $\mathrm{F}_{\mathrm{DO}_{2}}$. This allows the patient to use his or her portable oxygen device for a longer period. Not all pediatric-size patients can utilize these oxygen-conserving devices because they require a trigger to separate inspiration from expiration. These trigger thresholds may be too difficult for smaller pediatric patients to use, so caution must be used when considering an oxygen-conserving device.

\section{Future}

\section{Automation of Oxygen Delivery}

As we have reviewed, oxygen therapy is the standard of care and has saved countless lives since its discovery. We understand the benefits and risks with oxygen therapy, but what does the future hold? One of the vulnerabilities in our current practice of oxygen therapy is the manual titration/dosing. This manual titration often leads to hypoxemia or hyperoxemia. A paper by Claure et al ${ }^{107}$ shows that, within a critical care environment with the highest level of patient monitoring, clinicians only reach their titration goals $64 \%$ of the time. This inability to adequately achieve oxygenation goals seems unacceptable and has led teams to develop and study the application of automated oxygen titration. Initially, this automation was limited to invasive and noninvasive ventilation serving neonate ${ }^{108,109}$ and adult patients, ${ }^{39}$ but it has now progressed to other forms of oxygen delivery. ${ }^{110}$ These devices have been able to significantly improve $\mathrm{S}_{\mathrm{pO}_{2}}$ within an intended target range while reducing the work load related to routine manual titration. This technology has the potential to improve care delivery and efficiency; however, sadly, none are available in the United States. Further research is needed to assess this technology in the older infant and child.

\section{Preoxygenation for Intubation}

Tracheal intubation in critical illness is associated with severe life-threating complications often relating to hypoxemia. Preoxygenation before intubation is recommended in an attempt to reduce these complications. In patients with severe hypoxemia requiring noninvasive ventilation or high levels of oxygen, removal of the mask for the procedure exposes the patient to a lower $\mathrm{F}_{\mathrm{DO}_{2}}$, which can lead to hypoxia. HFNC has the ability to continue providing a high level of oxygen during the intubation. This has led to the creation of ongoing research to evaluate the safety and effectiveness of using HFNC to avoid a hypoxia event in the severely ill. ${ }^{111,112}$ HFNC during intubation appears to show promise, but further research is needed in pediatrics.

\section{Intravenous Oxygenation}

Another evolving concept is the delivery of oxygen intravenously. Kheir et al ${ }^{113}$ were able to develop an injectable foam suspension containing self-assembling, lipid- 
based microparticles encapsulating a core of pure oxygen gas for intravenous injection. When the microparticles were infused by intravenous injection into hypoxemic rabbits, arterial saturations increased within seconds to nearly normal levels. This is an encouraging demonstration of hypoxemic situations, showing that animals can survive and remain healthy after 10-15 min of complete asphyxia. However, before you hear "pass the $\mathrm{IVO}_{2}$," additional research will be needed to assess the removal of $\mathrm{CO}_{2}$, lipid oxygen microparticle metabolism, and possible long-term effects of infusions.

\section{Summary}

There is no doubt oxygen therapy is important and has saved many lives. Oxygen administration should be considered in the same way as other drugs and titrated to a measured end point to avoid excessive or inadequate dosing. Withholding oxygen can have detrimental effects; however, continuing to provide oxygen therapy when it is no longer indicated can prolong hospitalization and increase the cost of care. Oxygen therapy is one aspect of oxygen delivery. One must ensure that oxygen content and cardiac output are adequate when assessing the effectiveness of oxygen therapy. Device selection is vitally important in pediatrics because not only is the size of our patients a variable, but what they will wear is an additional consideration. Oxygen therapy has several physiologic effects and toxicities similar to those in adults. Nevertheless, there are several differences that if neglected can lead to compromise (eg, poor perfusion, congenital heart disease, retinopathy of prematurity in the preterm) and/or brain injury.

\section{REFERENCES}

1. Partington JR. A short history of chemistry, 3rd edition. New York: Dover Publications; 1989:90.

2. Fisher AB. Oxygen therapy: side effects and toxicity. Am Rev Respir Dis 1980;122(5 Pt 2):61-69.

3. James S, Lanman JT. History of oxygen therapy and retrolental fibroplasia. Prepared by the American Academy of Pediatrics, Committee on Fetus and Newborn with the collaboration of special consultants. Pediatrics 1976;57(suppl 2):591-642.

4. Saugstad OD. Oxygen toxicity in the neonatal period. Acta Paediatr Scand 1990;79(10):881-892.

5. Hess J. Oxygen unit for premature and very young infants. Am J Dis Child 1934;47:916-917.

6. Robertson AF. Reflections on errors in neonatology: I. The "handsoff" years, 1920 to 1950. J Perinatol 2003;23(1):48-55.

7. Zanardo V, Freato F. Home oxygen therapy in infants with bronchopulmonary dysplasia: assessment of parental anxiety. Early Hum Dev 2001;65(1):39-46.

8. Egan DF, Scanlan CL, Wilkins RL, Stoller JK. Egan's fundamentals of respiratory care. St. Louis, Missouri: Mosby; 1999:358-360.

9. Cole CH, Wright KW, Tarnow-Mordi W, Phelps DL, Pulse Oximetry Saturation Trial for Prevention of Retinopathy of Prematurity
Planning Study Group. Resolving our uncertainty about oxygen therapy. Pediatrics 2003;112(6 Pt 1):1415-1419.

10. Tin W. Oxygen therapy: 50 years of uncertainty. Pediatrics 2002; 110(3):615-616.

11. Finer NN, Rich WD. Neonatal resuscitation: raising the bar. Curr Opin Pediatr 2004;16(2):157-162.

12. Anderson CG, Benitz WE, Madan A. Retinopathy of prematurity and pulse oximetry: a national survey of recent practices. J Perinatol 2004;24(3):164-168.

13. Higgins RD, Bancalari E, Willinger M, Raju TN. Executive summary of the workshop on oxygen in neonatal therapies: controversies and opportunities for research. Pediatrics 2007;119(4):790-796.

14. Walsh M, Engle W, Laptook A, Kazzi SN, Buchter S, Rasmussen $\mathrm{M}$, et al. Oxygen delivery through nasal cannulae to preterm infants: can practice be improved? Pediatrics 2005;116(4):857-861.

15. Sola A, Saldeño YP, Favareto V. Clinical practices in neonatal oxygenation: where have we failed? What can we do? J Perinatol 2008;28(Suppl 1):S28-S34.

16. dos Santos ML, Fleischer G, Beppu OS, Neves JC, Ratto OR. [Alveolar-arterial oxygen difference (A-a)DO2), pulmonary shunt (Qs/Qt), and dead space/tidal volume relation (VD/VT) in healthy children]. AMB Rev Assoc Med Bras 1976;22(4):121-124.

17. Welch B. Oxyhemoglobin dissociation. JACEP 1979;8(1):48.

18. Poets CF. When do infants need additional inspired oxygen? A review of the current literature. Pediatr Pulmonol 1998;26(6):424428.

19. Rodríguez-Roisin R, Roca J. Mechanisms of hypoxemia. Intensive Care Med 2005;31(8):1017-1019.

20. Kacmarek RM, Stoller JK, Heuer AJ, Egan DF. Egan's fundamentals of respiratory care. St. Louis, Missouri: Elsevier/Mosby; 2013: 868-870.

21. Martin DS, Grocott MP. III. Oxygen therapy in anaesthesia: the yin and yang of $\mathrm{O}_{2}$. Br J Anaesth 2013;111(6):867-871.

22. Walsh BK. Neonatal and pediatric respiratory care, 4th edition. Amsterdam: Elsevier; 2015;157-158.

23. Guyton AC. Textbook of medical physiology. Philadelphia: WB Saunders Company; 2005:492.

24. West JB. Pulmonary pathophysiology: the essentials. Baltimore: Lippincott Williams \& Wilkins; 2007:6.

25. Schreiner RL, Kisling JA. Practical neonatal respiratory care. New York: Raven Press; 1982:332.

26. Kallstrom TJ, American Association for Respiratory Care. AARC clinical practice guideline: oxygen therapy for adults in the acute care facility: 2002 revision and update. Respir Care 2002;47(6): 717-720.

27. Loftus BC, Ahn J, Haddad J Jr. Neonatal nasal deformities secondary to nasal continuous positive airway pressure. Laryngoscope 1994;104(8 Pt 1):1019-1022.

28. Robertson NJ, McCarthy LS, Hamilton PA, Moss AL. Nasal deformities resulting from flow driver continuous positive airway pressure. Arch Dis Child Fetal Neonatal Ed 1996;75(3):F209-F212.

29. Williams R, Rankin N, Smith T, Galler D, Seakins P. Relationship between the humidity and temperature of inspired gas and the function of the airway mucosa. Crit Care Med 1996;24(11):1920-1929.

30. Kelly MG, McGarvey LP, Heaney LG, Elborn JS. Nasal septal perforation and oxygen cannulae. Hosp Med 2001;62(4):248.

31. Kopelman AE, Holbert D. Use of oxygen cannulas in extremely low birthweight infants is associated with mucosal trauma and bleeding, and possibly with coagulase-negative staphylococcal sepsis. J Perinatol 2003;23(2):94-97.

32. Negus VE. Humidification of the air passages. Thorax 1952;7(2): 148-151. 


\section{Pediatric OXYgen Therapy}

33. American Association for Respiratory Care, Restrepo RD, Walsh BK. Humidification during invasive and noninvasive mechanical ventilation: 2012. Respir Care 2012;57(5):782-788.

34. American Academy of Pediatrics Subcommittee on Diagnosis and Management of Bronchiolitis. Diagnosis and management of bronchiolitis. Pediatrics 2006;118(4):1774-1793.

35. Ralston SL, Lieberthal AS, Meissner HC, Alverson BK, Baley JE, Gadomski AM, et al. Clinical practice guideline: the diagnosis, management, and prevention of bronchiolitis. Pediatrics 2014; 134(5):e1474-e1502.

36. Cunningham S, Rodriguez A, Adams T, Boyd KA, Butcher I, Enderby $\mathrm{B}$, et al. Oxygen saturation targets in infants with bronchiolitis (BIDS): a double-blind, randomised, equivalence trial. Lancet 2015;386(9998):1041-1048.

37. Abdelsalam M, Cheifetz IM. Goal-directed therapy for severely hypoxic patients with acute respiratory distress syndrome: permissive hypoxemia. Respir Care 2010;55(11):1483-1490.

38. Gilbert-Kawai ET, Mitchell K, Martin D, Carlisle J, Grocott MP. Permissive hypoxaemia versus normoxaemia for mechanically ventilated critically ill patients. Cochrane Database Syst Rev 2014;(5): CD009931.

39. Martin DS, Grocott MP. Oxygen therapy in critical illness: precise control of arterial oxygenation and permissive hypoxemia. Crit Care Med 2013;41(2):423-432.

40. Marini JJ. Too much for too long-wrong targets, wrong timing? Crit Care Med 2013;41(2):664-665.

41. Bert P, Hitchcock MA, Hitchcock FA. Barometric pressure. Columbus, Ohio: College Book Company; 1943:362.

42. Jenkinson SG. Physiologic response to exposure to $100 \%$ inspired oxygen. Respir Care 1983;28:614.

43. Nunn JF. Conscious volunteers developed hypoxemia and pulmonary collapse when breathing air and oxygen at reduced lung volume. Anesthesiology 2003;98(1):258-259.

44. Jackson RM. Pulmonary oxygen toxicity. Chest 1985;88(6):900905.

45. Crapo JD. Morphologic changes in pulmonary oxygen toxicity. Annu Rev Physiol 1986;48:721-731.

46. Saugstad OD. Bronchopulmonary dysplasia-oxidative stress and antioxidants. Semin Neonatol 2003;8(1):39-49.

47. O'Donovan DJ, Fernandes CJ. Free radicals and diseases in premature infants. Antioxid Redox Signal 2004;6(1):169-176.

48. Saugstad OD. Oxygen for newborns: how much is too much? J Perinatol 2005;25(Suppl 2):S45-S49; discussion S50.

49. Thomson L, Paton J. Oxygen toxicity. Paediatr Respir Rev 2014; 15(2):120-123.

50. Pacher P, Beckman JS, Liaudet L. Nitric oxide and peroxynitrite in health and disease. Physiol Rev 2007;87(1):315-424.

51. Finer N, Leone T. Oxygen saturation monitoring for the preterm infant: the evidence basis for current practice. Pediatr Res 2009; 65(4):375-380

52. Baba L, McGrath JM. Oxygen free radicals: effects in the newborn period. Adv Neonatal Care 2008;8(5):256-264.

53. Thomas W, Speer CP. Nonventilatory strategies for prevention and treatment of bronchopulmonary dysplasia: what is the evidence? Neonatology 2008;94(3):150-159.

54. Saugstad OD. Oxidative stress in the newborn: a 30-year perspective. Biol Neonate 2005;88(3):228-236.

55. de Jonge E, Peelen L, Keijzers PJ, Joore H, de Lange D, van der Voort PH, et al. Association between administered oxygen, arterial partial oxygen pressure and mortality in mechanically ventilated intensive care unit patients. Crit Care 2008;12(6):R156.

56. Eastwood G, Bellomo R, Bailey M, Taori G, Pilcher D, Young P, Beasley R. Arterial oxygen tension and mortality in mechanically ventilated patients. Intensive Care Med 2012;38(1):91-98.
57. Cabello JB, Burls A, Emparanza JI, Bayliss S, Quinn T. Oxygen therapy for acute myocardial infarction. Cochrane Database Syst Rev 2010;(6):CD007160

58. Wijesinghe M, Perrin K, Ranchord A, Simmonds M, Weatherall M, Beasley R. Routine use of oxygen in the treatment of myocardial infarction: systematic review. Heart 2009;95(3):198-202.

59. Fonnes S, Gögenur I, Søndergaard ES, Siersma VD, Jorgensen LN, Wetterslev J, Meyhoff CS. Perioperative hyperoxia: long-term impact on cardiovascular complications after abdominal surgery, a post hoc analysis of the PROXI trial. Int J Cardiol 2016;215:238243.

60. Modi P, Imura H, Caputo M, Pawade A, Parry A, Angelini GD, Suleiman MS. Cardiopulmonary bypass-induced myocardial reoxygenation injury in pediatric patients with cyanosis. J Thorac Cardiovasc Surg 2002;124(5):1035-1036.

61. del Nido PJ, Mickle DA, Wilson GJ, Benson LN, Coles JG, Trusler GA, Williams WG. Evidence of myocardial free radical injury during elective repair of tetralogy of Fallot. Circulation 1987;76(5 Pt 2):V174-V179.

62. del Nido PJ, Benson LN, Mickle DA, Kielmanowicz S, Coles JG, Wilson GJ. Impaired left ventricular postischemic function and metabolism in chronic right ventricular hypertrophy. Circulation 1987;76(5 Pt 2):V168-V173.

63. del Nido PJ, Mickle DA, Wilson GJ, Benson LN, Weisel RD, Coles $\mathrm{JG}$, et al. Inadequate myocardial protection with cold cardioplegic arrest during repair of tetralogy of Fallot. J Thorac Cardiovasc Surg 1988;95(2):223-229.

64. Caputo M, Mokhtari A, Miceli A, Ghorbel MT, Angelini GD, Parry $\mathrm{AJ}$, et al. Controlled reoxygenation during cardiopulmonary bypass decreases markers of organ damage, inflammation, and oxidative stress in single-ventricle patients undergoing pediatric heart surgery. J Thorac Cardiovasc Surg 2014;148(3):792-801.e8; discussion $800-801$.

65. Vilalta A, Sahuquillo J, Merino MA, Poca MA, Garnacho A, Martínez-Valverde T, Dronavalli M. Normobaric hyperoxia in traumatic brain injury: does brain metabolic state influence the response to hyperoxic challenge? J Neurotrauma 2011;28(7):11391148.

66. Moler FW, Meert K, Donaldson AE, Nadkarni V, Brilli RJ, Dalton HJ, et al. In-hospital versus out-of-hospital pediatric cardiac arrest: a multicenter cohort study. Crit Care Med 2009; 37(7):2259-2267

67. Meaney PA, Nadkarni VM, Cook EF, Testa M, Helfaer M, Kaye W, et al. Higher survival rates among younger patients after pediatric intensive care unit cardiac arrests. Pediatrics 2006;118(6): 2424-2433.

68. Davis PG, Tan A, O'Donnell CP, Schulze A. Resuscitation of newborn infants with $100 \%$ oxygen or air: a systematic review and meta-analysis. Lancet 2004;364(9442):1329-1333.

69. Rabi Y, Rabi D, Yee W. Room air resuscitation of the depressed newborn: a systematic review and meta-analysis. Resuscitation 2007; 72(3):353-363.

70. Saugstad OD, Ramji S, Soll RF, Vento M. Resuscitation of newborn infants with $21 \%$ or $100 \%$ oxygen: an updated systematic review and meta-analysis. Neonatology 2008;94(3):176-182.

71. Tan A, Schulze A, O'Donnell CP, Davis PG. Air versus oxygen for resuscitation of infants at birth. Cochrane Database Syst Rev 2005; (2):CD002273.

72. Harling AE, Beresford MW, Vince GS, Bates M, Yoxall CW. Does the use of $50 \%$ oxygen at birth in preterm infants reduce lung injury? Arch Dis Child Fetal Neonatal Ed 2005;90(5):F401F405. 


\section{Pediatric OXYgen Therapy}

73. Naumburg E, Bellocco R, Cnattingius S, Jonzon A, Ekbom A. Supplementary oxygen and risk of childhood lymphatic leukaemia. Acta Paediatr 2002;91(12):1328-1333.

74. Spector LG, Klebanoff MA, Feusner JH, Georgieff MK, Ross JA. Childhood cancer following neonatal oxygen supplementation. J Pediatr 2005;147(1):27-31.

75. Wyckoff MH, Aziz K, Escobedo MB, Kapadia VS, Kattwinkel J, Perlman JM, et al. Part 13: Neonatal Resuscitation: 2015 American Heart Association guidelines update for cardiopulmonary resuscitation and emergency cardiovascular care (reprint). Pediatrics 2015; 136(Suppl 2):S196-S218.

76. Bennett KS, Clark AE, Meert KL, Topjian AA, Schleien CL, Shaffner $\mathrm{DH}$, et al. Early oxygenation and ventilation measurements after pediatric cardiac arrest: lack of association with outcome. Crit Care Med 2013;41(6):1534-1542.

77. Ferguson LP, Durward A, Tibby SM. Relationship between arterial partial oxygen pressure after resuscitation from cardiac arrest and mortality in children. Circulation 2012;126(3):335-342.

78. Kilgannon JH, Jones AE, Shapiro NI, Angelos MG, Milcarek B, Hunter K, et al. Association between arterial hyperoxia following resuscitation from cardiac arrest and in-hospital mortality. JAMA 2010;303(21):2165-2171.

79. Kilgannon JH, Jones AE, Parrillo JE, Dellinger RP, Milcarek B, Hunter K, et al. Relationship between supranormal oxygen tension and outcome after resuscitation from cardiac arrest. Circulation 2011;123(23):2717-2722.

80. Bellomo R, Bailey M, Eastwood GM, Nichol A, Pilcher D, Hart GK, et al. Arterial hyperoxia and in-hospital mortality after resuscitation from cardiac arrest. Crit Care 2011;15(2):R90.

81. Atkins DL, Berger S, Duff JP, Gonzales JC, Hunt EA, Joyner BL, et al. Part 11: Pediatric basic life support and cardiopulmonary resuscitation quality: 2015 American Heart Association guidelines update for cardiopulmonary resuscitation and emergency cardiovascular care (reprint). Pediatrics 2015;136(Suppl 2):S167-S175.

82. Copublishing of the Pediatric and Neonatal Portions of the 2015 International Consensus on Cardiopulmonary Resuscitation and Emergency Cardiovascular Care Science With Treatment Recommendations and the 2015 American Heart Association Guidelines Update for Cardiopulmonary Resuscitation and Emergency Cardiovascular Care. Pediatrics 2015;136(Suppl 2):S83-S87.

83. Davies P, Cheng D, Fox A, Lee L. The efficacy of noncontact oxygen delivery methods. Pediatrics 2002;110(5):964-967.

84. Myers TR, American Association for Respiratory Care. AARC clinical practice guideline: selection of an oxygen delivery device for neonatal and pediatric patients: 2002 revision and update. Respir Care 2002;47(6):707-716.

85. Cairo JM, Pilbeam SP. Mosby's Respiratory Care Equipment, 6th edition. St Louis, Missouri: Mosby Elsevier; 1999:58.

86. Whittaker K. Comprehensive perinatal and pediatric respiratory care, 3rd edition. Clifton Park, New York: Delmar Cengage Learning; 2001:260.

87. Finer NN, Bates R, Tomat P. Low flow oxygen delivery via nasal cannula to neonates. Pediatr Pulmonol 1996;21(1):48-51.

88. Wilkinson D, Andersen C, O'Donnell CP, De Paoli AG. High flow nasal cannula for respiratory support in preterm infants. Cochrane Database Syst Rev 2011;(5):CD006405.

89. Dani C, Pratesi S, Migliori C, Bertini G. High flow nasal cannula therapy as respiratory support in the preterm infant. Pediatr Pulmonol 2009;44(7):629-634.

90. Holleman-Duray D, Kaupie D, Weiss MG. Heated humidified highflow nasal cannula: use and a neonatal early extubation protocol. J Perinatol 2007;27(12):776-781.
91. Walsh BK, Brooks TM, Grenier BM. Oxygen therapy in the neonatal care environment. Respir Care 2009;54(9):1193-1202.

92. Sreenan C, Lemke RP, Hudson-Mason A, Osiovich H. High-flow nasal cannulae in the management of apnea of prematurity: a comparison with conventional nasal continuous positive airway pressure. Pediatrics 2001;107(5):1081-1083.

93. Locke RG, Wolfson MR, Shaffer TH, Rubenstein SD, Greenspan JS. Inadvertent administration of positive end-distending pressure during nasal cannula flow. Pediatrics 1993;91(1):135-138.

94. Spence KL, Murphy D, Kilian C, McGonigle R, Kilani RA. Highflow nasal cannula as a device to provide continuous positive airway pressure in infants. J Perinatol 2007;27(12):772-775.

95. Mayfield S, Jauncey-Cooke J, Hough JL, Schibler A, Gibbons K, Bogossian F. High-flow nasal cannula therapy for respiratory support in children. Cochrane Database Syst Rev 2014;(3): CD009850.

96. Beggs S, Wong ZH, Kaul S, Ogden KJ, Walters JA. High-flow nasal cannula therapy for infants with bronchiolitis. Cochrane Database Syst Rev 2014;(1):CD009609.

97. Baudin F, Gagnon S, Crulli B, Proulx F, Jouvet P, Emeriaud G. Modalities and complications associated with the use of high-flow nasal cannula: experience in a pediatric ICU. Respir Care 2016; 61(10):1305-1310.

98. Mikalsen IB, Davis P, Øymar K. High flow nasal cannula in children: a literature review. Scand J Trauma Resusc Emerg Med 2016; 24:93.

99. ten Brink F, Duke T, Evans J. High-flow nasal prong oxygen therapy or nasopharyngeal continuous positive airway pressure for children with moderate-to-severe respiratory distress? Pediatr Crit Care Med 2013;14(7):e326-e331.

100. Pham TM, O’Malley L, Mayfield S, Martin S, Schibler A. The effect of high flow nasal cannula therapy on the work of breathing in infants with bronchiolitis. Pediatr Pulmonol 2015;50(7): 713-720.

101. Lamb K, Piper D. Southmedic OxyMask compared with the Hudson RCI Non-Rebreather mask: safety and performance comparison. Can J Respir Ther 2016;52(1):13-15.

102. Paul JE, Hangan H, Hajgato J. The OxyMask development and performance in healthy volunteers. Med Devices (Auckl) 2009;2: 9-17.

103. Beecroft JM, Hanly PJ. Comparison of the OxyMask and Venturi mask in the delivery of supplemental oxygen: pilot study in oxygen-dependent patients. Can Respir J 2006;13(5):247-252.

104. Schroeder AR, Marmor AK, Pantell RH, Newman TB. Impact of pulse oximetry and oxygen therapy on length of stay in bronchiolitis hospitalizations. Arch Pediatr Adolesc Med 2004;158(6):527530.

105. Quinonez RA, Garber MD, Schroeder AR, Alverson BK, Nickel W, Goldstein J, et al. Choosing wisely in pediatric hospital medicine: five opportunities for improved healthcare value. J Hosp Med 2013; 8(9):479-485.

106. McCulloh R, Koster M, Ralston S, Johnson M, Hill V, Koehn K, et al. Use of intermittent vs continuous pulse oximetry for nonhypoxemic infants and young children hospitalized for bronchiolitis: a randomized clinical trial. JAMA Pediatr 2015;169(10): 898-904.

107. Claure N, Bancalari E. Automated closed loop control of inspired oxygen concentration. Respir Care 2013;58(1):151-161.

108. Zapata J, Gómez JJ, Araque Campo R, Matiz Rubio A, Sola A. A randomised controlled trial of an automated oxygen delivery algorithm for preterm neonates receiving supplemental oxygen without mechanical ventilation. Acta Paediatr 2014;103(9):928933. 
109. Hallenberger A, Poets CF, Horn W, Seyfang A, Urschitz MS, CLAC Study Group. Closed-loop automatic oxygen control (CLAC) in preterm infants: a randomized controlled trial. Pediatrics 2014; 133(2):e379-e385

110. Lellouche F, L'her E. Automated oxygen flow titration to maintain constant oxygenation. Respir Care 2012;57(8):12541262.

111. Jaber S, Molinari N, De Jong A. New method of preoxygenation for orotracheal intubation in patients with hypoxaemic acute respiratory failure in the intensive care unit, non-invasive ven- tilation combined with apnoeic oxygenation by high flow nasal oxygen: the randomised OPTINIV study protocol. BMJ Open 2016;6(8):e011298-.

112. Simon M, Wachs C, Braune S, de Heer G, Frings D, Kluge S. High-flow nasal cannula oxygen versus bag-valve-mask for preoxygenation before intubation in subjects with hypoxemic respiratory failure. Respir Care 2016;61(9):1160-1167.

113. Kheir JN, Scharp LA, Borden MA, Swanson EJ, Loxley A, Reese $\mathrm{JH}$, et al. Oxygen gas-filled microparticles provide intravenous oxygen delivery. Sci Transl Med 2012;4(140):140ra88.

\section{Discussion}

Berlinski: I would just like to make a comment and ask a couple of questions. The first thing is, in my experience, I often see that $\mathrm{O}_{2}$ is not treated as a drug since you don't have to remove it from an automated medication-dispensing system and you can turn it up and down. Health-care providers make lots of changes, sometimes without consideration to other things that you mentioned. There is something else you mentioned that is concerning to me, at least when it comes to HFNC. Practitioners tend to disregard the maximum flow recommended for a specific size cannula by the manufacturer. Those practitioners ignore the fact that the diameter of the nasal prong is a determinant of the maximal flow and that any increase above it results in generation of back pressure and potential accidents. That has been very hard to drill into to people using these devices. The question is how do you deal with feeding while on HFNC? That's an issue, especially for infants and young children with bronchiolitis. How low of a flow is considered safe for oral feeds? At the 2016 American Thoracic Society conference, there were some animal studies suggesting that a flow as low as $4 \mathrm{~L} / \mathrm{min}$ might be safe. What do others do? It's always a discussion among pediatricians, speech therapists, and everybody else caring for these patients.

Sweet: The question I didn't get an answer to is what are the lowest saturations that we should tolerate? For a drop in the $\mathrm{S}_{\mathrm{aO}_{2}}$ by $5 \%$, you should only have to increase the cardiac output by a similar amount to compensate. Patients who live with saturations in the 80s also increase their $\mathrm{Hb}$ over time. Did you find anything in the literature to support defining the lower saturation limit for patients with acute bronchiolitis?

Walsh: I didn't find any evidence, in other words a trial that actually compared that. I did find a lot of practice, particularly around BPD and cor pulmonale; in saturations $<90$, people were more likely to develop cor pulmonale, but not 92 . I was surprised to see in the PALICC group ${ }^{1}$ - and since Ira [Cheifetz] was part of that group he can maybe comment about that-I was surprised to see them actually do 92, because to me it also should be derived from your $\mathrm{F}_{\mathrm{IO}_{2}}$ requirement. In other words, if you require $24 \% \mathrm{O}_{2}$ to keep your saturation at 92 that's probably $\mathrm{OK}$ for me, but if it requires $100 \% \mathrm{O}_{2}$ to keep you at 92 , maybe 88 or 85 is OK. I think we have to balance that $\mathrm{O}_{2}$ toxicity effect.

Cheifetz: I will go through this issue in much more detail later, but you are right; when you look at the PALICC recommendations ${ }^{1,2}$ for mild to moderate lung injury, the target oxygen saturation is $92 \%$. However, as lung injury becomes more severe, the recommended (by expert opinion) saturation goal does decrease based on the perceived risks and benefits. Unfortunately, there are no definitive data in pediatrics to provide absolute cutoffs for oxygen saturation targets regarding what is safe and what is not. Unfortunately, except for extrapola- tion from some neonatal and adult data, we are still left with expert opinion.

Stokes: One of the things I struggle with still is that you mentioned the toxicity of high $\mathrm{F}_{\mathrm{IO}_{2}}$ and when we get into situations where we have need for prolonged high $\mathrm{F}_{\mathrm{IO}_{2}}$. At some point, very high oxygen concentrations (even tolerating low saturations) injure the lung beyond hope of recovery, but I don't believe we have good data on either the $\mathrm{F}_{\mathrm{IO}_{2}}$ level or duration when further therapy is futile.

Walsh: No, actually, one of the first slides talked about the different types of hypoxemia: acute, chronic, and those types of things. I think that needs to be well defined in studies of hypoxemia. A lot of times, acute hypoxemia where a goal of 88 is OK or 85 by expert opinion for less than a week duration and when you're balancing high $\mathrm{F}_{\mathrm{IO}_{2}}$ values to maintain those lower saturations. But chronically, when it goes on for months, I wonder if there aren't some negative effects. I know in adults, studies of chronic hypoxia in the low 80 s requiring $\mathrm{O}_{2}$ therapy have showed benefit of home $\mathrm{O}_{2}$ therapy over the years. I don't know of anything in pediatrics, which is why I put that table up there because I think that's the way we need to look at: Is it acute or is it chronic in the particular studies?

Panitch: Going back to your questions about lowest safe saturations, I think you have to consider the type of patient you're talking about. A child with no underlying cardiorespiratory disease who has acute hypoxemia can 
tolerate lower saturations fairly well for several days, whereas in an infant with BPD, those lower saturations may have more repercussions with regard to pulmonary artery pressures and airway function. In the same way, when prescribing chronic supplemental $\mathrm{O}_{2}$ therapy, we know that episodic hypoxemia in infants with BPD can result in poor growth, and we have to consider that in terms of lowest safe saturations as well. Some people wean children from supplemental $\mathrm{O}_{2}$ using a gradual reduction in flow, whereas others might choose gradually increasing blocks of time off supplemental $\mathrm{O}_{2}$. When we talk about chronic $\mathrm{O}_{2}$ therapy, is there a better strategy for withdrawal?

Walsh: That's one of the things I'm a little worried about with HFNC: that I'm going to stand here 10 years from now and do another one of these lectures, and we find that HFNC actually lengthens the stay. Because right now I think people don't know how to wean it, which gets back to Ariel's [Berlinski] comment of how do you escalate but also how do you de-escalate this therapy? Some people have no rhyme or reason: "Oh, I do $1 \mathrm{~L}$ per day." Well, if you stretch that out for $16 \mathrm{~L}$, that's $16 \mathrm{~d}$ before you' $\mathrm{d}$ actually come off. Or when is it OK to go to $5 \mathrm{~L}$ and go off to simple $\mathrm{O}_{2}$ and those types of things. I didn't find anything in the literature, unfortunately, about how to escalate or de-escalate. I also think escalation is important because I would like us to potentially go to positivepressure ventilation when we get into the higher levels of $\mathrm{F}_{\mathrm{IO}_{2}}$ versus just sitting there on $80 \% \mathrm{O}_{2}$ on HFNC just because we can. I think that may be OK for the short term, but I worry that we'll get into trouble if we then intubate someone. We've had some negative events in which they were on high $\mathrm{F}_{\mathrm{IO}_{2}}$ and HFNC, and then you do a rapid sequence intubation and they fall apart and even arrest because you can't preoxygenate them and you can't ventilate them any better than what they're doing on their own with a high level of $\mathrm{O}_{2}$. So that becomes problematic. When it comes to reduction, particularly in the neonatal world, they tend to be a little more methodical in clinic; come in and wean and do trials. I did see one study where they did a 30 min trial off oxygen to determine if their $\mathrm{S}_{\mathrm{pO}_{2}}$ would drop below $92 \%$ with activity. If it didn't go below 92 they kept them off $\mathrm{O}_{2}$ and followed up with them a week later to make sure that was OK. I'm getting into big data as well, but one of the things I'm also very interested in is monitoring at home. In other words, if you make a decision like that in clinic, can you actually have a pulse oximeter that can send you that data over the next week so they don't have to come back in if everything looks good? If you get no note, if you will, from the system and you assume everything is great. That's an evolving process right now with wearables and things like that that I think is exciting, at least for adults. This technology hasn't quite gotten to pediatrics yet, but hopefully it will come down to us.

Cheifetz: I am sorry if this question overlaps with a previous one. You presented excellent data on bronchiolitis and how pulse oximetry is associated with an increased stay. Similarly, I believe we have a subset of patients with bronchiolitis who are managed with HFNC and may not actually need it. Although there are no definitive data, it is likely that we are keeping some of these infants in the ICU and, potentially, the hospital longer than necessary. Furthermore, I wonder if our general weaning strategies for HFNC, even in those who do benefit from this approach, are too slow (sometimes painfully slow!), again increasing length of ICU and/or hospital stay. We need more data to better guide our management approaches. Do you have thoughts or comments?

Walsh: I agree. It is painfully slow a lot of times because I think we aren't sure of what we're doing. I think there are also some additional benefits that are outside $\mathrm{O}_{2}$ therapy. Humidification is one of those benefits; we call our hospitals a healing environment, but it host the driest air. Patients on simple $\mathrm{O}_{2}$, even though we put those bubble humidifiers in line, they add absolutely no humidity to the gas stream. Not only that; they're dehydrated because they stopped eating before they were admitted for their respiratory illness. So they're dehydrated, and we give them dry gas and those types of things. With HFNC, I'm trying to maintain equipoise that it may actually be beneficial from the humidity perspective. Also efficiency, so dead space washout may actually help them get over their illness, but I'm very concerned about weaning and that we just don't know how fast we can go. Or when we need to escalate.

Cheifetz: I want to come back to Ariel's first point, because I believe you were let off the hook much too quickly when he asked about your thoughts on feeding and HFNC. Kyle [Rehder] and I looked at each other during those comments because this is a big issue for us at Duke. What insight do you have in terms of feeding during HFNC therapy, especially in the infant population? Any guidelines and/or suggestions you could offer?

Walsh: I wish I did, but I don't. A couple things I didn't have time to show were measured pressures, particularly in the ears, from complications that people have been concerned that HFNC is too loud and too much pressure. What they're finding out is that the pressure is pretty low, even at the higher flows and even in infants. Or equivocal to low levels of CPAP. So what I tell people is, if in your practice in your institution you let infants feed while on CPAP, then you can probably let them feed on HFNC. If you do not on one then you probably should not on the other, because your stance that you've taken is that 
even at low levels of pressure, you don't feel comfortable feeding. I've heard that other places use breathing frequency, so if they're too tachypneic even on HFNC, you wouldn't do it, but if you were able to normalize their breathing frequency or get it in a zone in which you were feel comfortable feeding someone, then maintain it and feed them.

Rehder: Just to add to that, I think there are 2 questions that frequently arise: When is it safe for oral feeding? And when is it safe for enteral feeding through a gastric tube? Post-pyloric feeding is likely yet another different scenario as to when it's safe to feed at a given flow.

Walsh: Certainly, a lot of people feed through a nasogastric tube on CPAP and even fairly high levels of CPAP. And post-pyloric too, some people do that. We're a big believer of that in our pediatric ICU at least. Bolus feeding versus continuous, all of those things are up for debate when it comes to feeding on CPAP or HFNC. It's a complex issue.

Fedor: A couple points about flow that you discussed, I wondered if you would comment on those. You talked about high flow versus low flow, and I think those of us who use HFNC know that when you get down to certain low flow, we experience a lot more rainout in the system, and then the patient can have complications that are associated with that. When you're talking about higher flow, I think that, depending on the delivery device, you have to look at the fact that some of the devices have pop-offs, and there are no audible alarms to indicate that the pop-off has occurred, so sometimes we don't even know what flow is being delivered to the patient. Could you comment on that?

Walsh: Yes, the systems are different, and I think that's something we have to consider as a profession of where we need that additional monitoring. Some systems have pop-offs, and some have higher pop-offs that you almost never exceed unless it gets pinched in a bedrail. Some have audible alarms where if it gets disconnected or pinched, it will alarm. Same thing with water levels and all these things. Some systems say it's simple $\mathrm{O}_{2}$ and they stick to that. I am not sure which is the right answer, but I do worry that if you're using this as respiratory support above simple $\mathrm{O}_{2}$, then it needs to be monitored like that. There are lots of different ways we can do it in the future; we are geniuses when it comes to monitoring patients, so we can hook up pressure monitors and those types of things to do that. One other comment about flow and prong size; it's another thing that's hotly debated. Some people feel that you should almost occlude the nares, and some think you should not. Obviously, the more you occlude the nares, the more nasopharyngeal pressure you can provide to the patient but maybe less dead space washout if you think about your Venturi-type effects where you're pulling in more clean air without $\mathrm{CO}_{2}$. Lower flow is something we need to think about and when we transition back to simple $\mathrm{O}_{2}$. Like I said earlier, I worry that it may lengthen stay. I understand that the practical therapist who's out there thinks we've already paid for the device and there's no harm and if anything it's probably good humidity being provided even at those lower flows; why not leave them on until they're ready to come off? But if you're having complications like rainout and spitting or it hinders them and it keeps them in their room-in other words, they can't get out and move around - then I think we should switch back to simple $\mathrm{O}_{2}$.

\section{REFERENCES}

1. Rimensberger PC, Cheifetz IM; Pediatric Acute Lung Injury Consensus Conference (PALICC) Group. Ventilatory support in children with pediatric acute respiratory distress syndrome: proceedings from the Pediatric Acute Lung Injury Consensus Conference. Pediatr Crit Care Med 2015;16(5 Suppl 1):S51-S60.

2. The Pediatric Acute Lung Injury Consensus Conference Group. Pediatric acute respiratory distress syndrome: consensus recommendations from the Pediatric Acute Lung Injury Consensus Conference. Pediatr Crit Care Med 2015;16(5):428-439.

3. Kotecha S, Allen J. Oxygen therapy for infants with chronic lung. Arch Dis Child Fetal Neonatal Ed 2002 87:F11-F14.

This article is approved for Continuing Respiratory Care Education credit. For information and to obtain your CRCE

(free to AARC members) visit

www.rcjournal.com

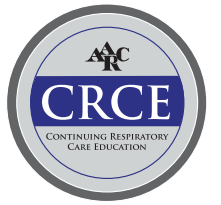

